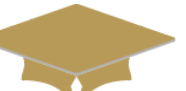

MEDRESEARCH

www.medresearch.in

\title{
A cross sectional study to estimate delay in diagnosis and treatment of tuberculosis (TB) among patients attending urban health centre in an urban slum area
}

\author{
S. Patel T. ${ }^{1}$, Goswami V. ${ }^{2 *}$, N. Lilhore K. ${ }^{3}$, S. Kuwatada J. ${ }^{4}$ \\ DOI: https://doi.org/10.17511/ijphr.2018.i1.01
}

1 Tarun S. Patel, Assistant Professor, Department of Community Medicine, Sri Aurobindo Medical College and PG Institute, Indore, Madhya Pradesh, India.

${ }^{2 *}$ V.P. Goswami, Assistant Professor, Department of Community Medicine, Index Medical College and Hospital and Research Centre, Indore, Madhya Pradesh, India.

3 Khilit N. Lilhore, PG Resident, Department of Community Medicine, Sri Aurobindo Medical College and PG Institute, Indore, Madhya Pradesh, India.

4 Jitesh S. Kuwatada, Consultant for immunisation, National Technical Support Unit for Immunisation, NIHFW, New Delhi, India.

Background: RNTCP (Revised National Tuberculosis Control Program) is an application in India of the (World Health Organisation) WHO recommended (Directly Observed Treatment Short Course) DOTS strategy. Objectives: To determine average delay on part of patient and health system in diagnosis of tuberculosis, treatment delay in starting DOTS and total delay. Methodology: A crosssectional descriptive study of 464 tuberculosis patients was conducted in an urban health center (UHC) of an urban slum area of Mumbai. Patients registered under RNTCP during 1 year i.e. from $1^{\text {st }}$ January to $31^{\text {st }}$ December 2016 were interviewed regarding their complaints and reporting to a health care facility (time taken and type-private or government), time taken for diagnosis and starting treatment. Results: Among 464 patients, mean patient's delay, health system delay and total delay were 21.09 days (median 15), 14.41 days (median 6) and 35.50 days (median 21) respectively. Almost $60 \%$ of total delay was constituted from patient's delay. Conclusion: Patient delay was significantly more among sputum negative pulmonary TB patients than sputum positive patients. Health system delay to diagnose TB was more if private practitioners were approached first.

Keywords: Tuberculosis, Patients delay, Health system delay, Total delay

\section{Corresponding Author}

V.P. Goswami, Assistant Professor, Department of Community Medicine, Index Medical College and Hospital and Research Centre, Indore, Madhya Pradesh, India.

Email: drvpgoswami@gmail.com
How to Cite this Article

Patel TS, Goswami VP, Lilhore KN, Kuwatada JS. A cross sectional study to estimate delay in diagnosis and treatment of tuberculosis (TB) among patients attending urban health centre in an urban slum area. Public Health Rev Int J Public Health Res. 2018;5(1):1-7.

Available From

https://publichealth.medresearch.in/index.php/ijphr/ article/view/75
Manuscript Received 2018-02-14

Conflict of Interest No

Review Round 1
2018-02-24
Funding
Nil

Review Round 2
2018-03-03
Ethical Approval
Yes

Review Round 3

Accepted 2018-03-07

(c) 2018 by Tarun S. Patel, V.P. Goswami, Khilit N. Lilhore, Jitesh S. Kuwatada and Published by Siddharth Health Research and Social Welfare Society. This is an Open Access article licensed under a Creative Commons Attribution 4.0 International License https://creativecommons.org/licenses/by/4.0/ unported [CC BY 4.0].

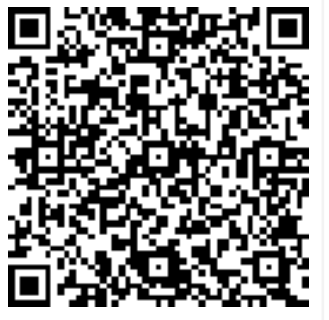




\section{Introduction}

Most of the estimated number of incident cases in 2016 occurred in the WHO South-East Asia region (45\%), the WHO African Region (25\%) and the WHO Western Pacific Region (17\%); smaller proportions of cases occurred in the WHO Eastern Mediterranean Region (7\%), the WHO European Region (3\%) and the WHO Region of the Americas $(3 \%)$.

Ten countries accounted for $76 \%$ of the total gap between TB incidence and reported cases; the top three were India (25\%), Indonesia (16\%) and Nigeria (8\%). An estimated 10.4 million people fell ill with TB in 2016: $90 \%$ were adults, $65 \%$ were male, $10 \%$ were peopleliving with HIV $(74 \%$ in Africa) and $56 \%$ were in five countries: India, Indonesia, China, the Philippines and Pakistan.

Ten countries accounted for $75 \%$ of the incidencetreatment enrolment gap for drug-resistant TB; India and China accounted for $39 \%$ of the global gap [1]. Any delay in diagnosis and consequently treatment of TB patients not only increases infectivity in the community but may also lead to more advance disease state which may result in more complication and expose them to higher risk of death.

Identifying delays in diagnosis and treatment occur and the factors related to specific types of delays can help tuberculosis control programs and medical care providers to target case-finding, diagnostic and treatment efforts appropriately [2].

The private sector in India is very large, and it is believed that more than half of all TB patients are cared for in the private sector [3]. This study is an attempt to identify various delays under RNTCP, in an urban slum area of Mumbai.

\section{Methodology}

Study design and study area: A cross-sectional descriptive study of 464 tuberculosis patients was conducted in an urban health centre (UHC) of a slum area of Mumbai. There were however a large number of Private Practitioners (PP's), Nursing homes, quacks and traditional healers in this slum area apart from the health post providing health services.

Study duration: During one year i.e. from 1st January to 31st December 2016.
Study population: Patients registered under RNTCP in the DOTS centre of the urban health centre (UHC), in an urban slum area of Mumbai.

Inclusion criteria: All patients who were diagnosed as TB and registered under RNTCP under the health post provided they were willing to participate in the study.

Exclusion criteria: Those patients who were not willing to participate in the study.

Sampling technique and sample size: Universal sampling method was used with sample size of 464 .

Study too land Data collection: Initial interview were taken for rapport building. After obtaining informed consent, patients were interviewed in detail with a pretested and semi-structured questionnairein the RNTCP OPD within seven days of their registration, regarding their complaints and reporting to a health care facility (time taken and type-private or government), time taken for diagnosis and starting treatment.

Thus patient, health system, treatment and total delay were calculated.

\section{Operational Definitions}

01. Case (New): A patient who has never had treatment for tuberculosis or who has taken anti-tuberculosis drugs for less than one month [4].

02. Case (pulmonary), Smear positive TB: A patient with at least two initial sputum smear examinations (direct smear microscopy) AFB+; or one sputum examination AFB+ and radiographic abnormalities consistent with active pulmonary tuberculosis as determined by a clinician; or one sputum specimen AFB+ and culture positive for M. Tuberculosis[4].

03. Case (pulmonary), smear negative: A patient with pulmonary tuberculosis not meeting the above criteria for smear-positive disease. Diagnostic criteria should include: at least three sputum smear examinations negative for AFB; and radiographic abnormalities consistent with active pulmonary tuberculosis; and no response to a course of broad-spectrum antibiotics; and a decision by a clinician to treat with a full course of antituberculosis chemo-therapy; or positive culture but negative AFB sputum examinations [4]. 
04. Patient delay- Time interval between onset of symptom and presentation to a health care provider [2].

05 . Health system delay- This is defined as time interval between the date of health-seeking behavior at a health care provider and the initiation of anti-tuberculosis treatment [2].

06. Treatment delay- This is defined as the duration in days between TB diagnosis and first treatment initiation [2].

07. Total delay- This is defined as the sum of patient and healthcare system delay [2].

Ethical consideration: Permission from the Institutional Ethics Committee was obtained prior to the start of the study. A written informed consent was obtained from each of the study participants prior to their interview.

Statistical analysis: Data were entered in Microsoft Excel sheet and statistical analysis was done using SPSS (Statistical Package for Social Sciences) version 23.0. Frequency distributions were calculated for all the variables. Patient delay, health system delay, treatment delay and total delay were calculated using mean and median.Oneway ANOVA was used for statistical analysis.

\section{Results}

Table 1 shows that, among 464 diagnosed TB patients, $421(90.73 \%)$ have pulmonary TB and 43 $(9.26 \%)$ have extra pulmonary TB. Among 421 pulmonary TB cases, $316(75 \%)$ patients had sputum positive TB; 105 (25\%) had sputum negative TB.

Table-1: Socio-demographic status of the patients-

\begin{tabular}{|l|l|l|l|}
\hline Variables & \multicolumn{1}{|c|}{ Category } & No. of patients & Percentage (\%) \\
\hline \multirow{4}{*}{ Age } & $10-20$ yrs & 130 & 28 \\
\cline { 2 - 4 } & $21-30$ yrs & 174 & 38 \\
\cline { 2 - 4 } & $31-40$ yrs & 65 & 14 \\
\cline { 2 - 4 } & $41-50$ yrs & 44 & 9 \\
\cline { 2 - 4 } & $51-70$ yrs & 51 & 11 \\
\hline \multirow{4}{*}{ Eender } & Male & 277 & 59.6 \\
\cline { 2 - 4 } & Female & 187 & 40.3 \\
\hline \multirow{5}{*}{ Education } & Illiterate & 94 & 20.3 \\
\cline { 2 - 4 } & Primary education & 188 & 40.6 \\
\cline { 2 - 4 } & Secondary education & 138 & 29.7 \\
\cline { 2 - 4 } & Graduation & 44 & 9.4 \\
\hline \multirow{4}{*}{} & Enskilled & 160 & 34.4 \\
\cline { 2 - 4 } & Housewife & 102 & 21.9 \\
\hline
\end{tabular}

\begin{tabular}{|l|l|l|l|}
\hline \multirow{5}{*}{ Per capita income } & Semi-skilled & 94 & 20.3 \\
\cline { 2 - 4 } & students & 80 & 17.2 \\
\cline { 2 - 4 } & Skilled & 28 & 6.3 \\
\hline & $<500$ & 113 & 24.2 \\
\cline { 2 - 5 } & $500-1999$ & 314 & 67.7 \\
\cline { 2 - 4 } & $2000-4999$ & 37 & 8.1 \\
\hline
\end{tabular}

Regarding the first health care facility visited for the complaints, $319(68.8 \%)$ patients approached private practitioners, $94(20.3 \%)$ approached the UHC and 51 (10.9\%) of them approached govt. tertiary care hospitals (medical colleges).

Regarding the chief complaints among the 464 patients, $365(78.6 \%)$ of patients had fever, cough and loss of appetite; 56 (12.1\%) had haemoptysis, chest pain, and breathlessness, 15 (3.1\%) suffered from abdominal pain, vomiting, diarrhoea, 29 $(6.3 \%)$ had swelling in neck.

Table 2 reveals types of delays and length of delay. Mean patient delay, health system delay; treatment (DOTS) delay and total delay were 21.09 days (median 15 days), 14.41 days (median 6 days), 2.84 days (median 3.19 days), 35.50 days (median 21 days), respectively.

Table-2: Various delays and length of delay.

\begin{tabular}{|l|l|l|l|}
\hline \multicolumn{1}{|c|}{ Type of delay } & \multicolumn{1}{|c|}{$\begin{array}{c}\text { Mean } \\
\text { (days) }\end{array}$} & \multicolumn{1}{|c|}{$\begin{array}{c}\text { Standard Deviation } \\
\text { (days) }\end{array}$} & \multicolumn{1}{|c|}{$\begin{array}{c}\text { Median } \\
\text { (days) }\end{array}$} \\
\hline Patient Delay & 21.09 & 19.65 & 15 \\
\hline Health-system delay & 14.41 & 17.26 & 6 \\
\hline $\begin{array}{l}\text { Delay in starting } \\
\text { DOTS }\end{array}$ & 2.84 & 3.19 & 3.19 \\
\hline Total delay & 35.50 & 23.077 & 21 \\
\hline
\end{tabular}

Table 3 depicts frequency distribution of number of days with respect to patient delay and health system delay.

Maximum patients $(62.5 \%)$ had patient delay of 1 17 days and $78.1 \%$ of patients had health system delay of $1-15$ days.

Table-3: Patient and Health System Delays.

\begin{tabular}{|l|l|l|l|l|l|}
\hline \multicolumn{3}{|c|}{ Patient delay } & \multicolumn{3}{c|}{ Health system delay } \\
\hline $\begin{array}{l}\text { Number of } \\
\text { days }\end{array}$ & $\begin{array}{l}\text { Number of } \\
\text { patients }\end{array}$ & $\begin{array}{l}\text { Percentage } \\
(\%)\end{array}$ & $\begin{array}{l}\text { Number of } \\
\text { days }\end{array}$ & $\begin{array}{l}\text { Frequen } \\
\text { cy }\end{array}$ & $\begin{array}{l}\text { Percentage } \\
(\%)\end{array}$ \\
\hline $1-15$ & 290 & 62.5 & $1-15$ & 363 & 78.1 \\
\hline $15-30$ & 88 & 18.8 & $15-30$ & 28 & 6.2 \\
\hline $30-45$ & 21 & 4.7 & $30-45$ & 45 & 9.4 \\
\hline $45-60$ & 65 & 14.1 & $45-60$ & 28 & 6.2 \\
\hline Total & 464 & 100.0 & Total & 464 & 100.0 \\
\hline
\end{tabular}

On applying ANOVA test, females had significantly more $(p=0.024)$ total delay than males. 
On applying ANOVA test, patient delay $(p=0.001)$ and total delay $(p=0.033)$ were found to be significantly more in sputum positive patients than sputum negative patients.

Table 4 depicts frequency distribution of number of days with respect to total delay and treatment delay. Total delay in $39.1 \%$ of patients was $1-25$ days, $35.9 \%$ of patients was $25-50$ days and in $25 \%$ of patients it was 50-75 days. Similarly, treatment (DOTS) delay in $90.6 \%$ of patients was $1-5$ days and in $4.7 \%$ of patients was 5-10 and $10-15$ days.

Table-4: Total delay and treatment delay.

\begin{tabular}{|l|l|l|l|l|l|}
\hline \multicolumn{3}{|c|}{ Total delay } & \multicolumn{3}{c|}{ Treatment delay } \\
\hline $\begin{array}{l}\text { Number of } \\
\text { Days }\end{array}$ & $\begin{array}{l}\text { Number of } \\
\text { patients }\end{array}$ & $\begin{array}{l}\text { Percentage } \\
(\%)\end{array}$ & $\begin{array}{l}\text { Number of } \\
\text { Days }\end{array}$ & $\begin{array}{l}\text { Number of } \\
\text { patients }\end{array}$ & $\begin{array}{l}\text { Percentage } \\
\%)\end{array}$ \\
\hline $1-25$ & 167 & 35.9 & $1-5$ & 420 & 90.6 \\
\hline $25-50$ & 181 & 39.1 & $5-10$ & 22 & 4.7 \\
\hline $50-75$ & 116 & 25.0 & $10-15$ & 22 & 4.7 \\
\hline Total & 464 & 100.0 & Total & 464 & 100.0 \\
\hline
\end{tabular}

Table 5 reveals a statistically significant difference observed between the health care system first approached and health system delay $(p=0.007)$ and total delay $(p=0.019)$.

Table-5: Comparison between various delays and health system approached first by the patients

\begin{tabular}{|l|l|l|l|l|l|}
\hline \multicolumn{2}{|c|}{$\begin{array}{c}\text { Health care system } \\
\text { visited first }\end{array}$} & $\begin{array}{c}\text { Patient } \\
\text { delay }\end{array}$ & $\begin{array}{c}\text { Health } \\
\text { system delay }\end{array}$ & $\begin{array}{c}\text { Total } \\
\text { delay }\end{array}$ & $\begin{array}{l}\text { Treatment } \\
\text { delay }\end{array}$ \\
\hline $\begin{array}{l}\text { Private } \\
\text { practitioners }\end{array}$ & Medianbn & 21.57 & 14.59 & 42.02 & 3.11 \\
\hline $\begin{array}{l}\text { Tertiary care } \\
\text { hospital }\end{array}$ & Median & 20.10 & 8.14 & 29.98 & 3.00 \\
\hline $\begin{array}{l}\text { Urban health } \\
\text { center }\end{array}$ & Median & 10.62 & 8.80 & 19.5 & 2.10 \\
\hline p value & 0.243 & 0.007 & 0.019 & 0.609 \\
\hline
\end{tabular}

A wide range of factors like ignorance (39.4\%), not utilizing health care due to domestic responsibilities $(19.8 \%)$, inadequate knowledge about the disease $(18.6 \%)$, fear or history of stigma $(11.4 \%)$, and female gender $(10.6 \%)$, were found to be responsible for the patient delay.

In the present study, among 464 TB patients, 277 (59.6\%) were males and 187 (40.3\%) females. According to NFHS-4, the prevalence of TB is higher among women (389 per lac) than among men (220 per lac) [5]. In a study conducted in Lagos, Nigeria, 141 patients were recruited. The mean age was $29.5 \pm 11.0$ years, $89(63 \%)$ were males and 52 (37\%) were females [6].

\section{Discussion}

Delay with respect to gender: In the study conducted in Bangladesh, women in comparison with men had significantly longer mean patient delay (51.9 vs.48.7days) [7]. In contrast in the study conducted in Tamil Nadu, men postponed seeking health care for longer period than women [8]. In another cross-sectional study of Malasia, gender was associated significantly with patient delay. Females appeared to have longer delay [9].

The mean total delay to TB diagnosis was 13.3 weeks $(95 \% \mathrm{CI} ; 11.5,15.1)$ for women and 11.4 weeks $(95 \% \mathrm{CI} ; 10.6,12.2)$ for men, including a patient's delay of 7.9 weeks $(95 \% \mathrm{CI} ; 6.5,9.3)$ and 7.6 weeks $(95 \% ; 6.9,8.3)$, respectively. Women do not receive a diagnosis of TB by doctors or other health care provider's as quickly as men once they seek health care [10].

Patient delay, health system delay, total delay and treatment delay: The study conducted in Tamil Nadu on pulmonary (new sputum positive) tuberculosis patients depicted that the median patient, health system and total delay were 20, 23 and 60 days respectively [9].

The study conducted in Amhara region of Ethiopia on pulmonary tuberculosis (new sputum positive) showed that the median total delay was 80 days. The median health-seeking period and health providers' delays were 15 and 61 days, respectively [11].

In a study done in Argentina among smear positive pulmonary TB patients, the mean diagnostic delays were as follows: mean total delay 92.1 days (median 62.0); mean patient delay 58.8 days (median 31); mean health service delay 32.6 days (median 12.5). The mean treatment delay was 0.9 days (median) [12].

The findings of a cross-sectional study performed in Tanzania on pulmonary tuberculosis (new sputum positive) revealed a mean patient's delay of 162 days, while mean total delay was 185 days, with nearly $90 \%$ of this being patient's delay. The mean health system delay was 23 days [13].

The findings of a study performed in 10 DOTS districts of Ethiopia revealed that the overall median patient delay was 30 days (mean $=60$ days). $53 \%$ [95\% Confidence Intervals (CI) (50\%, 56\%)] of patients had delayed their first consultation for $\geq 30$ days [14]. 
The magnitude of patient delay was $165(52.4 \%)$ and median of patient delay was 30 days within range of 3 to 270 days [15]. Study conducted in Ethiopia shows, the median patient delay was 60 days and mean 78.2 days [16].

In a study conducted in Lagos, Nigeria, the median patient delay was eight weeks; median doctor delay was one-week, median treatment delay was one week, and the median total delay was 10 weeks. Doctor delay was observed in 19 (13\%) patients.

Patient delay was the most frequent type of delay observed and was the major contributor to the overall total delay [7].

The median delay from the onset of cough to first visit to the clinic was 60 days with a rangeof 3-180 days. The prevalence of prolong patient delay was $63(61.8 \%)$. Reasons given byrespondents with prolonged delay included health facility too far $22.2 \%$, lack of awarenessof DOTs service on time $12.7 \%$, and domestic work prevented coming on time $9.5 \%$. Majority $(52.4 \%)$ did not give any specific reason [17].

Delay with respect to sputum positive and sputum negative: Study at Ethiopia showed health service delay was (median 6 days; mean 9.5 days) significantly lower in smear positives compared to smear negatives [16].

In the cross-sectional study conducted in Taiwan, sputum negative smear TB patients had a longer health system delay [18].

Delay with respect to health facility visited first: The study conducted in Tamil Nadu, the patient delay was greater if the patient had initially consulted a government dispensary and the total delay resulted largely from a long patient delay when government providers were consulted first and a long health system delay when private providers were consulted first [9].

In the study conducted in Kampala, patients often presented to private clinics $(36.8 \%)$, drug shops or pharmacies $(39.4 \%)$ more commonly than government health units $(14 \%)$ as initial contacts [19].

In the study conducted in Ethiopia, patients first visiting a health post/clinic, or a private medical provider experienced longer health system delay compared to those who visited government health centres or hospitals [11].
In the study conducted in North west Ethiopia, prior to patient's first consultation at a public health facility, patients received treatment from a variety of informal sources: The Orthodox Church, where they were treated with holy water $(24 \%)$; private practitioners $(13 \%)$; rural drug vendors $(7 \%)$; and traditional healers (3\%). The delay was higher for patients who used informal treatment (median 31 days) than those who did not (15 days) [15].

Illiterate $(A O R=6.18,95 \% \mathrm{CI}: 1.34,28.43)$, extra pulmonary tuberculosis ( $A O R=10.12,95 \% \mathrm{CI}: 3.07$, 33.37), living greater than a distance of $10 \mathrm{~km}$ from TB service in health facilities (AOR $=3.55,95 \%$ CI:1.17,10.80), prior visited with holy water $(A O R=10.55,95 \% \mathrm{CI}: 3.99,27.89)$, with traditional healer $(A O R=4.29,95 \% C I: 1.13,16.37)$ and with private drug store/pharmacy (AOR=6.81，95\% $\mathrm{CI}: 2.47,18.78$ ) were determinants of patients delay for first consultation in health facilities [16].

Study done at Lagos, Nigeria, 104 (74\%) patients consulted with various types of hospitals as the first place for seeking help while 37 (26\%) went to other places such as chemists and prayer houses. More patients went to private hospitals than any other type of facility.

Prior to presentation at the chest clinic, 19 (14\%) patients did not go to any hospital at all while 98 (70\%) visited one hospital and $24(17 \%)$ visited between two to four hospitals. Ninety (64\%) patients were referred to the chest clinic by doctors, $22(16 \%)$ came by themselves and $29(21 \%)$ were brought by friends and relatives [6].

The strength of this studywas that it identifies the gaps in the implementation of RNTCP which could be improved and taken into account by the policy makers or further research. The findings are from an urban slum area which are the hubs of tuberculosis.

The limitations were, this study doesn't deal with the cause of patient delay \& health system delay. Reasons for approaching a particular health facility were not asked.

\section{Conclusion}

The mean patient delay was found to be 21 days, mean health system delay was 14 days, mean total delay 35 days and treatment delay was of 2.8 days.

Total delay was significantly more among female patients as compared to male patients. 
Patient delay was significantly more among sputum negative pulmonary TB patients than sputum positive patients.

Health system delay to diagnose TB was more if private practitioners were approached first by the patients.Only $11 \%$ (35) pulmonary TB patients were advised sputum examination as the first investigation by private general practitioners.

\section{Reference}

01. World Health Organization. Global TB report. 2017.

[Crossref]

02. World Health Organization. Diagnosis and treatment delay in tuberculosis, An in-depth analysis of the health seeking behavior of patients and health system response in seven countries of the Eastern Mediterranean Region. Available from: [Article] [Crossref]

03. Srinath S, Sreenivas AN, Sarabjit SC, Roopa S, Geetanjali S, Subhash $Y$, et al. From where are Tuberculosis patients accessing treatment in India?- Results from a cross-sectional community-based survey of 30 districts. PLoS ONE. 2011;6(9)e24160.

doi: $10.1371 /$ journal.pone.0024160 [Crossref]

04. Definitions and reporting framework for tuberculosis-2013 revision. (updated December 2014) (WHO/HTM/ TB/2013,2). Geneva- WHO. 2013.

Available From: [Article] [Crossref]

05. International Institute for Population Sciences (IIPS). National Family Health Survey (NFHS-4). 2015-16; India.

Available From: [Article] [Crossref]

06. Olumuyiwa O, Babafemi J. Patterns of delay among pulmonary tuberculosis patients attending a Lagos Chest clinic, Lagos Nigeria. BMC Pub Health. $2004 ; 4 ; 18$.

[Crossref]

07. Karim F, Islam MA, Chowdhury AM, Johansson E, Diwan VK. Gender differences in delays in diagnosis and treatment of tuberculosis. Health Policy Plan. 2007;Sep;22(5)329-34.

[Crossref]
08. Rajeswari R, Chandrasekaran V, Suhadev M, Sivasubramaniam S, Sudha G, Renu G. Factors associated with patient and health system delays in the diagnosis of tuberculosis in SouthIndia. Int J Tuberc Lung Dis. 2002;Sep;6(9)789-95.

[Crossref]

09. Chang CT, Esterman A. Diagnostic delay among pulmonary tuberculosis patients in Sarawak, Malaysia: a cross-sectional study. Rural Remote Health. 2007 Apr-Jun;7(2)667.

[Crossref]

10. Long $\mathrm{NH}$, Johansson $\mathrm{E}$, Lönnroth $\mathrm{K}$, Eriksson $\mathrm{B}$, Winkvist $A$, Diwan VK. Longer delays in tuberculosis diagnosis among women in Vietnam. Int J Tuberc Lung Dis. 1999 May;3(5)388-93.

[Crossref]

11. Solomon Y, Gunnar B, Getu A. Diagnostic and treatment delay among pulmonary tuberculosis patients in Ethiopia- A cross sectional study. BMC Infec Dis. 2005;5;112.

[Crossref]

12. Zerbini E, Chirico MC, Salvadores B, Amigot B, Estrada S, Algorry G. Delay in tuberculosis diagn osis and treatment in four provinces of Argent ina. Int J Tuberc Lung Dis. 2008 Jan;12(1) 63-8. [Crossref]

13. Wandwalo ER, Mørkve O. Delay in tuberculosis C ase-finding and treatment in Mwanza, Tanzania. Int J Tuberc Lung Dis. 2000Feb;4(2)133-8. [Crossref]

14. Mesfin MM, Newell JN, Walley JD, Gessessew A, Madeley RJ. Delayed consultation among pulmonary tuberculosis patients- a cross sectional study of 10 DOTS districts of Ethiopia. BMC Public Health. 2009 Feb 9;9;53. doi: $10.1186 / 1471-2458-9-53$ [Crossref]

15. Yeshiwork AM, Lakew A, Netsanet F, Shegaon $A B$, Addisu WK. Delay for first consultation and associated factors among tuberculosis patients in Bahir Dar Town administration, North West Ethiopia. Amer J Health Res. 2014;2;140-5. [Crossref]

16. Demissie M, Lindtjorn B, Berhane Y. Patient and health service delay in the diagnosis of pulmonary tuberculosis in Ethiopia. BMC Public Health. 2002 Sep;25;2;23.

[Crossref] 
17. Fatiregun AA, Ejeckam CC. Determinants of patient delay in seeking treatment among pulmonary tuberculosis cases in a government specialist hospital in Ibadan, Nigeria. Tan J Health Res. $2010 ; 12 ; 2$.

[Crossref]

18. Chiang $C Y$, Chang CT, Chang RE, Li CT, Huang RM. Patient and health system delays in the diagnosis and treatment of tuberculosis in Southern Taiwan. Int J Tuberc Lung Dis. 2005 Sep;9(9)1006-12.

[Crossref]
19. Mpungu SK, Karamagi C, Mayanja KH. Patient and health service delay in pulmonary tuberculosis patients attending a referral hospital. BMC Pub Health. 2005;5;122. [Crossref]

20. Sherman LF, Fujiwara PI, Cook SV, Bazerman LB, Frieden TR. Patient and health care system delays in the diagnosis and treatment of tuberculosis. Int J Tuberc Lung Dis. 1999 Dec; 3(12)1088-95.

[Crossref] 